\title{
Mechanisms of plasminogen activator inhibitor 1 action in stromal remodeling and related diseases
}

\author{
Jelena Milenkovic ${ }^{\mathrm{a}}$, Maja Milojkovic ${ }^{\mathrm{a}}$, Tatjana Jevtovic Stoimenov ${ }^{\mathrm{b}}$, Boris Djindjic ${ }^{\mathrm{a}}$, Edita Miljkovic
}

\begin{abstract}
Plasminogen activator inhibitor type 1 (PAI-1) is the main physiologic inhibitor of fibrinolysis. However, it is also involved in many physiological processes such as extracellular matrix (ECM) proteolysis and remodeling, cell adhesion, motility, and apoptosis, angiogenesis, etc. The aim of the study was to summarize current knowledge and gain insights into the mechanisms of PAI- 1 action in the processes of stromal remodeling and diseases with considerable matrix pathologies (atherosclerosis, tissue fibrosis, cancer metastasis, pregnancy related complications, etc). As a component of an early cellular response to injury, PAl-1 reacts with membrane surface proteins and participates in the initiation of intracellular signaling, specifically cytoskeletal reorganization and motility. Complexity of ECM homeostasis resides in varying relation of the plasminogen system components and other matrix constituents. Inflammatory mediators (transforming growth factor- $\beta$ and interferon- $\gamma$ ) and hormones (angiotensin II) are in the close interdependent relation with PAI-1. Also, special attention is devoted to the role of increased PAI-1 concentrations due to the common $4 \mathrm{G} / 5 \mathrm{G}$ polymorphism. Some of the novel mechanisms of ECM modification consider PAI-1 dependent stabilization of urokinase mediated cell adhesion, control of the vascular endothelial cadherin trafficking and interaction with endothelial cells proteasome, its relation to matrix metalloproteinase 2 and osteopontin, and oxidative inhibition by myeloperoxidase. Targeting and/or alteration of PAl-1 functions might bring benefit to the future therapeutic approaches in diseases where ECM undergoes substantial remodeling.
\end{abstract}

Key words: fibrinolysis, cellular adhesion and migration, tissue fibrosis, embryo implantation, cancer metastasis

Received: July 30, 2017; Accepted: October 20, 2017; Available online: November 2, 2017

https://doi.org/10.5507/bp.2017.046

anstitute of Pathophysiology, Faculty of Medicine University of Nis, Serbia

'Institute of Biochemistry, Faculty of Medicine University of Nis, Serbia

'Hematology and Clinical Immunology Clinic, Clinical Center in Nis, Serbia

Corresponding author: Jelena Milenkovic, e-mail:jelenaradovic982@gmail.com

\section{INTRODUCTION}

Plasminogen activator inhibitor type 1 (PAI-1) is a multifunctional protein involved in a number of physiologic processes, where it may exhibit its procoagulant, antiadhesive, proinflammatory, profibrotic or (anti)proteolytic effects. It is the main physiologic inhibitor of fibrinolysis; specifically tissue plasminogen activator (t-PA) and urokinase plasminogen activator (u-PA or urokinase). Through its effects on PAs, PAI-1 regulates plasmin and matrix metalloproteinases (MMP) activity and consequently tissue homeostasis ${ }^{1-3}$. However, the nature of its role in various biological processes is not always clear, and may comprise inhibition of fibrinolysis, extracellular matrix (ECM) proteolysis, cell adhesion, motility, and apoptosis, angiogenesis, etc. Beside the well-known influence of increased PAI-1 concentrations toward venous and arterial thrombosis, active PAI-1 involvement is determined in the pathogenesis of atherosclerosis, pulmonary fibrosis, cancer, and pregnancy related complications. Special attention has been devoted to its increased concentration due to the common $4 \mathrm{G} / 5 \mathrm{G}$ polymorphism in the PAI- 1 gene promoter region ${ }^{1-7}$.

Various cytokines, as well as growth factors and hormones, can induce PAI-1 mRNA transcription. Some of these are interleukin-1 (IL-1) $\left(\right.$ ref. $\left.^{8}\right)$, tumor necrosis factor- $\alpha($ TNF- $\alpha)$ (ref. $\left.{ }^{9}\right), \beta$-fibroblast growth factor (FGF) $\left(\right.$ ref. $\left.^{10}\right)$, transforming growth factor- $\beta$ (TGF- $\left.\beta\right)\left(\right.$ ref. $\left.^{9}\right)$, angiotensin II (AII) (ref. ${ }^{5}$ ), thrombin ${ }^{11}$, etc. There are three conformational forms of PAI-1: active, latent, and substrate form. The active form spontaneously converts into a stable latent conformation. PAI-1 interaction with other proteins can stabilize its active conformation and prolong activity. Such is the association with vitronectin (VN), a protein that binds PAI-1 with high affinity in plasma, subendothelial matrix or platelets. VN is abundantly present in subendothelial matrix and may preserve PAI-1 activity in this compartment, making it physiologically relevant in ECM (ref. $\left.{ }^{12-14}\right)$.

Extracellular matrix remodeling is controlled by the balance between proteases and their inhibitors. Plasminogen system is implicated in the processes of ECM degradation, where plasmin regulates pericellular proteolysis by the cleavage of MMPs, collagen, fibronectin, fibrin, proteoglycans. PAI- 1 contributes to the both physiologic and pathophysiologic tissue/stromal remodeling, and thus takes essential part in wound healing process $^{1,13,14}$.

The aim of the study was to summarize current knowledge and gain insights into the mechanisms of PAI-1 action in the processes of stromal remodeling and diseases with considerable matrix pathologies. 


\section{STROMAL REMODELING IN THE WOUND HEALING PROCESS}

Wound healing is a dynamic process with distinct phases that require hemostasis, inflammation, tissue proliferation and differentiation. Beside well known antiproteolytic role of soluble PAI-1, the matrix-bound PAI-1 exerts important non-proteolytic actions in wound healing. In the initial stage, a significant increase of PAI-1 and $\mathrm{u}-\mathrm{PA}$ were seen at the outermost edge of the wound, particularly in the newly deposited matrix as matrix-bound proteins. Concomitant increase of u-PA and u-PA receptor (u-PAR) is observed on migrating cells at their leading edge ${ }^{15-17}$. PAI-1 is shown to be prominent molecule of the early G0 to G1 transition transcriptome of human keratinocytes cell line, while the keratinocyte growth factor, secreted by the stromal fibroblasts during wound closure, is a powerful stimulator of PAI-1 expression ${ }^{15}$. The PAI-1 transcripts reached maximum at $2 \mathrm{~h}$ and were substantially decreasing at $4 \mathrm{~h}$ post-stimulation, which responds to mid G1 phase $^{18}$.

Urokinase initiated plasminogen activation is mainly required for pericellular proteolysis. Binding of u-PA to uPAR at the cell surface activates plasminogen and enhances extracellular proteolysis ${ }^{16}$. At the same time, through the u-PA initiated conformational change of u-PAR, and associated adapter proteins, intracellular signaling is initiated, specifically - mechanical force transmission to the cytoskeleton. The u-PAR change makes it more attracted toward VN and integrins ${ }^{17,19,20}$ and their interaction induce different molecular pathways (mitogen-activated protein kinase (MAPK), tyrosine kinases, Ras/extracellular-regulated signal kinase (ERK), etc), leading to cytoskeleton reorganization and cell migration. Thus, u-PA stimulates migration by uncovering a chemotactic epitope in u-PAR $\left(\right.$ ref. $\left.^{21-23}\right)$.

PAI-1 enhances cellular motility through the both adhesion and deadhesion processes, depending on the local conditions. Normally, cells can anchor to the matrix's $\mathrm{VN}$ through their integrins or u-PAR molecules. When $\mathrm{VN}$ is present in sufficient amount, PAI-1 will bind it and thus inhibit cell adhesion by blocking u-PAR and integrin binding sites ${ }^{17,24}$. The VN binding sites (somatomedin B domain) for PAI-1, u-PAR and integrin are clustered together and are overlapping, so these molecules may behave competitively. Additionally, PAI-1 has much higher affinity toward VN than u-PAR (ref. ${ }^{19,25}$ ). The local levels of VN and PAI-1 in ECM determine their promoting or inhibiting migration effect. Individually they have promigratory effect on vascular smooth muscle cells (SMC), but when together they form high-affinity complexes that annul promigratory effect of each other. Also, PAI-1 may convert $\mathrm{VN}$ to a self-associated multivalent form with enhanced cell/matrix binding properties (Fig. 1a) (ref. ${ }^{22,26}$ ).

PAI-1 participates in cell detachment in a VN independent manner, which requires PAI-1 to u-PA binding and

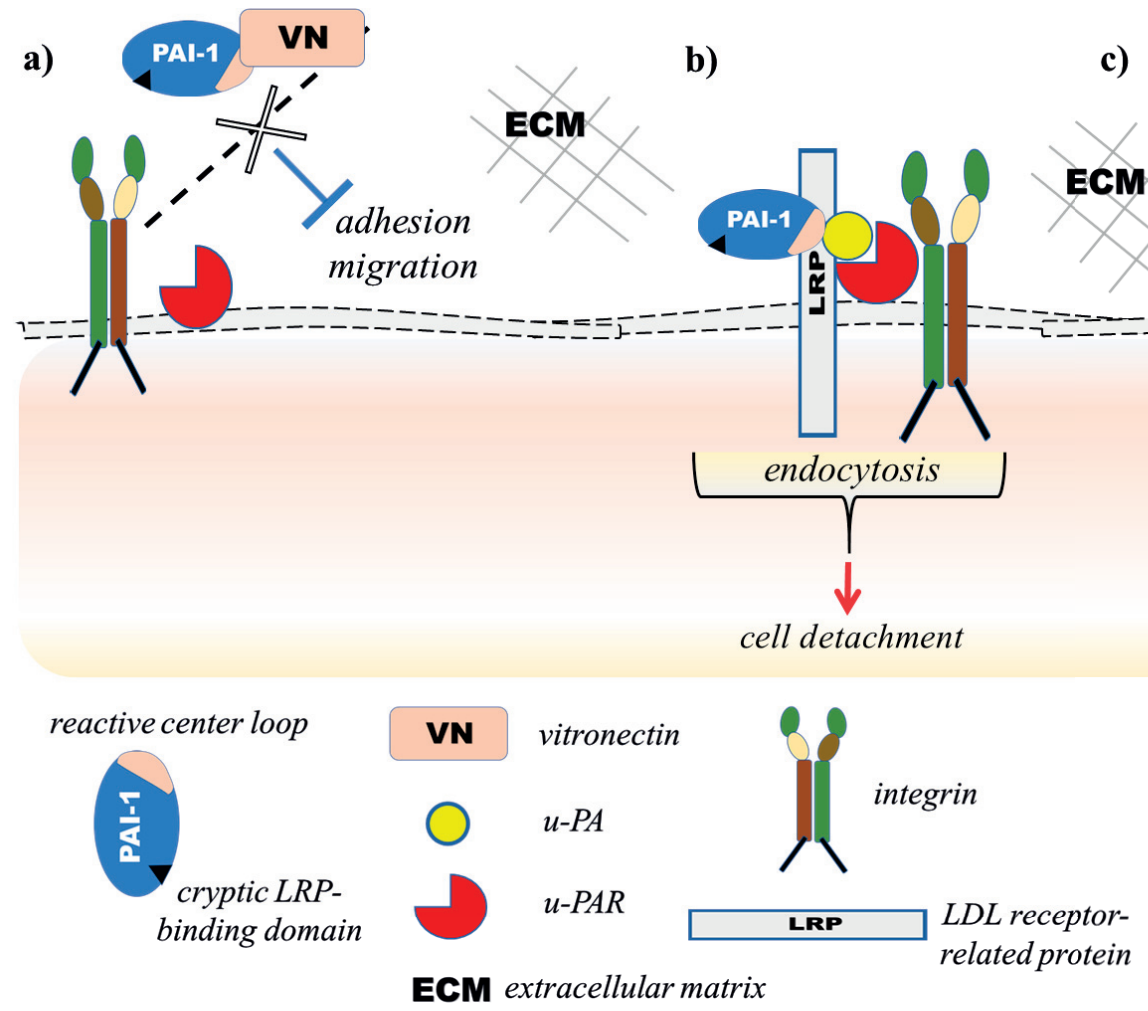

Fig. 1. Possible interactions of PAI-1 with cell surface molecules and its effects.

a) PAI-1 binds VN with high affinity causing inhibition of cell adhesion and motility; b) formation, internalization and inactivation of PAI-u-PA-u-PAR complex via LRP receptor causes cell to detach; c) PAI-1 binds to LRP via secondary interaction site and activates intracellular signaling that stimulates migration. PAI-1 - plasminogen activator inhibitor 1, VN - vitronectin, u-PA - urokinase plasminogen activator, u-PAR - u-PA receptor, LRP - low-density lipoprotein (LDL) receptor-related protein, ECM - extracellular matrix, JAK - Janus kinase, STAT - signal transducer and activator of transcription. 
is associated with decrease in u-PAR-integrin complexes at the cell surface. Adequate concentrations of u-PA and PAI-1 lead to formation, internalization and inactivation of PAI-u-PA-u-PAR complex via LRP - \{low-density lipoprotein (LDL) receptor-related protein (LRP) \} dependent process $^{4,27,28}$. When PAI-1 covalently attaches to u-PA in a solution, it blocks u-PA-induced cell migration (PAI-1u-PA is inactive). The PAI-1-u-PA complex may bind with high affinity to u-PAR and cause its internalization. The PAI-1-u-PA becomes degraded intracellularly, while u-PAR is being recycled back to the surface. The complex internalization causes the cell to detach from ECM (Fig. 1b) $\left(\right.$ ref $\left.^{28,29}\right)$. If u-PAR internalization is blocked, PAI-1-u-PA complex is turned into a chemoattractant. This means that PAI-1 can detach cells from other ECM proteins without direct binding to them (fibronectin and type I collagen) (ref. $\left.{ }^{20}\right)$. However, significantly fewer cells detach compared to $\mathrm{VN}$ because these proteins have multiple binding sites for integrins unlike $\mathrm{VN}$ (ref. ${ }^{19}$ ). When bound to PA, PAI-1 losses affinity for VN, which could restore $\mathrm{VN}$ attachment site for $\mathrm{VN}$ receptor integrins at the cell surface. Meaning that local PA do not only initiate proteolysis and ECM degradation, but also helps to expose cell-attachment sites for the cell migration ${ }^{30}$.

Additionally, PAI-1 can induce chemotaxis without u-PA involvement in vitro ${ }^{29}$. Active and inactive PAI-1 were shown to activate the JAK/STAT signaling system, with LRP being obligatory mediator, and thus stimulate cell migration. Non-complexed PAI-1 binds to LRP through the second site in PAI-1 molecule that is distinct from the one in PA-PAI-1 complexes (Fig. 1c) (ref. ${ }^{31}$ ). Taken together, PAI-1 involvement in cell-matrix interaction can be partially explained through its different bonding affinity toward proteases and adhesive proteins, where it modulates the accessibility of protein's cell-attachment sites $^{30}$. One of the newer studies report that u-PA and plasmin cleave VN. This process requires u-PA-u-PAR-VN binding and has negative impact on cell adhesion. PAI-1 was shown to counteract this function by stabilizing uPAR mediated cell adhesion to VN (ref. ${ }^{16}$ ).

Several studies potentiate PAI-1 inhibitory effect on cell migration and its contribution to delay in wound closure. By blocking u-PA, PAI-1 hinders plasmin formation and ECM proteolysis. Second mechanism is disruption of cellular bond to VN (ref. ${ }^{24,32}$ ). Regarding this, significantly faster wound closure was determined in PAI-1 knockout (KO) mice, than wild-type (WT) $\left(\right.$ ref. $\left.^{33}\right)$. Also, higher fibrinolytic activity in PAI-1 (-/-) mice produced less fibrin and thus impaired cell migration/adhesion, because the amount of tissue fibrin affects migration. In contrast, PAI-1 $(+/+)$ mice had higher fibrin levels and increased adhesion ${ }^{3}$.

\section{ADVERSE VASCULAR REMODELING AND PAI-1}

Participation in tissue remodeling gives PAI-1 a great importance in diseases where ECM undergoes change or damage (cardiovascular diseases, cancer, brain injury, obesity, bone remodeling). In regard, PAI-1 is involved in the injured vessel repair and regulation of intima formation $^{1,4,12,34}$. Neointima hyperplasia refers to the proliferation and migration of vascular SMCs in the intima that results in its thickening. Endothelial denudation is the primary injury event which triggers an inflammatory reaction, hemostasis, and fibrinolysis. Endothelial cells (EC) produce growth factors necessary for SMC proliferation (FGF, PDGF, TGF- $\beta$ ), while leukocytes release cytokines, among which NF- $\kappa$ B, TNF- $\alpha$ and IL- $1 \beta$ are pivotal for neointima formation ${ }^{5,26}$. In reply, TNF- $\alpha$ stimulates ECs to form microparticles on their surface which provide an area for u-PA/u-PAR mediated plasmin formation, supporting endothelial involvement in proteolytic activities (angiogenesis) necessary for SMC migration ${ }^{35}$.

Animal studies provided opposite results on neointima formation depending on the PAI-1 genotype, type of vascular injury, phases of wound healing, part of the vasculature, and presence of other clotting factors ${ }^{4,26,36}$. Upon vascular injury PAI-1 levels correlate with neointima formation while thrombus formation and fibrin deposition further modulate its anti-fibrinolytic effect. Thrombin, PAI-1, and VN were found co-localized at the site of vascular injury and atherosclerotic lesion. In association with VN, PAI-1 is an efficient local inhibitor of thrombin, in vitro and in vivo, that can block thrombin induced SMC proliferation $^{36-39}$.

Deposited fibrin serves as a chemotactic agent that promotes cell migration to the injury site. $\mathrm{VN}$ mediated PAI-1 binding to fibrin clots is dependent on direct VNfibrin interaction ${ }^{3,40}$. The presence or absence of thrombus and fibrin on neointima led to contradicting observations on PAI-1 effects in animal model studies ${ }^{36,38,41}$. In contrast to ferric chloride, mechanical and electrical injuries of mouse vessels are not associated with significant thrombus formation, thus the cell migration occurs in the absence of fibrin. High PAI-1 levels could impede neointima formation through the inhibition of $\mathrm{u}-\mathrm{PA}$ mediated proteolysis, which would stabilize ECM; or by binding to VN and prevention of $\mathrm{u}$-PAR-integrin mediated cell attachment ${ }^{37}$. However, severe electric injury causes extensive fibrin deposition in both WT and transgenic mice overexpressing PAI-1. The transgenic mice had significantly reduced in situ fibrinolytic activity but comparable intima/ media ratios, and SMC distribution pattern. Increased PAI-1 levels did not affect neointima formation at the injury with extensive fibrin deposition ${ }^{41}$.

Hasenstab and colleagues ${ }^{42}$ found that during carotid artery injury by angioplasty, expression of two proteins were changed, PAI-1 and tissue inhibitor of MMP-2. The expression was primarily increased in medial SMCs, confirming the importance of proteolytic activity for SMC migration in response to injury. In vitro PAI-1 overexpression increased mural thrombus accumulation in early phase (1 week) after injury ${ }^{34}$, but reduced intimal thickening and neointimal area (30\% at 1 week), without altering matrix accumulation. Local PAI-1 overproduction in injured vessel wall decrease plasmin production and consequently MMPs activation leading to reduced remodeling ${ }^{2}$. On 
the other hand, the same experiment showed PAI-1 overexpression accelerated re-endothelization of the injured $\operatorname{arteries}^{34}$.

Promotor of the PAI-1 gene contains regulatory elements including TGF- $\beta$ response site ${ }^{43}$. TGF- $\beta 1$ stimulates PAI-1 expression in the artery wall and promotes neointima growth through the PAI-1 dependent pathways. TGF- $\beta 1$ overexpressing PAI- 1 (-/-) mice did not show increased intimal growth, matrix accumulation, cell migration or proliferation. Also, they secreted 6- to 10-fold more TGF- $\beta 1$ than WT mice, suggesting PAI- 1 was a negative regulator of TGF- $\beta 1$ and a mediator of intimal growth $^{44}$. Plasmin exerts proteolytic activity on TGF- $\beta$ and is required for its conversion from latent to active form. Decreased plasmin production would decrease TGF- $\beta$ activation and thus increase SMC proliferation ${ }^{1,2}$.

Another mechanism by which PAI-1 may modulate vascular wall is cell apoptosis. Elevated intracellular PAI1 levels were associated with induced apoptosis. Its direct interaction with $\alpha-3$ subunit of proteasome in ECs prevented degradation of p53 and inhibitor of kappa B (IкBa) $\left(\right.$ ref. $\left.^{45}\right)$. Also, atherosclerotic vessel apoptotic cells lining correlated with components of plasminogen activation system and the PAI-1 inhibition of VN dependent cell adhesion. PAI-1 induced double increase in apoptosis of umbilical-vein ECs and vascular SMCs adherent to VN in vitro, independently of u-PA ( ref. $\left.^{41}\right)$.

\section{PAI-1 IN ATHEROSCLEROSIS AND MYOCARDIAL INFARCTION}

Increased PAI-1 blood levels are shown to be an independent risk factor for coronary artery disease, myocardial infarction (MI), and cerebrovascular events, as well as atherosclerosis progression and complications, such as plaque rupture or restenosis ${ }^{4,46}$. Locally elevated PAI-1 levels are observed in atherogenic lesions of coronary arteries $^{47}$ and advanced atherosclerotic plaques ${ }^{34}$. Mechanisms by which elevated plasma PAI-1 may affect atherosclerosis is the inhibition of fibrin clearance from plaques (ineffective fibrinolysis) and possible change in cellular content, especially SMC (ref. ${ }^{1-4}$ ). PAI-1 gene expression was found upregulated in macrophages and SMCs in human atherosclerotic lesions ${ }^{37,47}$, while oxidized LDL upregulated PAI-1 expression in ECs and SMCs in vitro ${ }^{37}$. Although fibrin formation and deposition participate in plaque growth, it is the primary event in the healing of damaged plaques. Also, we must consider concurrent increase in tissue factor expression ${ }^{48}$ and PAs levels ${ }^{47}$ within the plaque. A meta-analysis in 2010 determined no association of PAI-1 4G/4G polymorphism with MI and coronary artery disease, but only a marginal association with atherosclerosis ${ }^{6}$.

Inflammation and increased $\mathrm{C}$-reactive protein (CRP) levels contribute to fibrin deposition and are risk factors for vein graft thrombosis after bypass surgery. Similarly to IL- 1 and TNF- $\alpha$, CRP is shown to induce PAI- 1 mRNA in ECs in vitro and in vivo, together with tissue factor ${ }^{2}$. At least part of the locally increased PAI-1 in the vascular wall, in the early stages after vein graft surgery, is proposed to originate from plasma PAI-1 transition due to the loss of ECs barrier ${ }^{48,49}$. Additionally, since AII stimulates the expression of PAI-1 gene, the conditions with renin-angiotensin-aldosterone (RAA) system activation are expected to have PAI-1 levels increased. Modulation of PAI-1 levels by AII depends upon timing, location, and its concentrations, thus PAI can be related to both vascular injury and recovery ${ }^{5}$.

Besides its causal role on MI development via coronary thrombosis, the plasminogen system influences tissue remodeling after MI. Various cardiac cells (cardiomyocytes, ECs, fibroblasts, mast cells) produce PAI-1 after MI (ref. ${ }^{49-51}$ ), which could further affect progression of left ventricle (LV) dysfunction. The increased PAI-1 expression may contribute to interstitial and perivascular cardiac fibrosis, demonstrated by ECM accumulation, through the potential PAI-1 mediated inactivation of PAs and MMPs (ref. ${ }^{51,52}$ ).

Askari and colleagues ${ }^{52}$ observed significant influence of myeloperoxidase (MPO) and PAI-1 in LV response immediately after acute MI. The MPO generated oxidants significantly chlorinated and inhibited PAI-1, which lead to increased u-PA and plasmin activity. Beside decreased leukocyte entry into the infarcted zone, MPO (-/-) mice displayed decreased oxidative inactivation of PAI-1 and plasmin activity. MPO null mice demonstrated preservation of LV function, while PAI-1 null mice had accelerated myocardial rupture. Cardiac rupture in acute MI was more frequent in t-PA (-/-), u-PAR (-/-), and PAI-1 (-/-) mice, while u-PA (-/-), MPO (-/-), and MMP-9 (-/-) were protected. However, u-PA (-/-) and plasminogen (-/-) mice had impaired scar formation and revascularization ${ }^{52,53}$. Plasminogen (-/-) mice had deprived inflammatory cells activation and infiltration into the infarcted myocardium, hindered necrosis removal, delayed healing, and abolished fibrous tissue formation, thus their infarcted myocardium remained thicker than in WT animals ${ }^{53,54}$.

Significant coronary perivascular fibrosis developed in operated (artery ligation) mice compared to "sham" and PAI-1 deficient mice. Important difference, that might significantly influence the results, is a different expression of cytokines TGF- $\beta$ and TNF- $\alpha$. Surgically treated mice had regional increase of these cytokines compared to other animals. Interestingly, plasma PAI-1 levels were increased in post-MI mice, but there was no upregulation of PAI-1 mRNA in other organs suggesting that cardiac sources contributed to the elevated plasma PAI-1 levels ${ }^{51}$.

\section{TISSUE FIBROSIS AND PAI-1}

PAI-1 involvement in fibrotic diseases is well documented $^{5,51,55}$. Tissue fibrosis is often a consequence of deregulated wound healing, where hyperactive fibroblasts produce excessive accumulation of ECM. Prolonged inflammation and fibrin accumulation contribute to the process, where inflammation triggers profibrotic cytokine signaling (such as TGF- $\beta$ ) that activates fibroblasts and stimulate transformation of endothelial, epithelial 
or hepatic stellate cells into myofibroblasts. The PAI-1 anti-fibrinolytic activity gives advantage to the fibrin accumulation, further modulating inflammatory and collagenproducing cell migration ${ }^{3,56}$.

Physiologically, elevated PAI-1 expression in the initial phase expedite wound healing by protecting ECM proteins. PAI-1 blocks u-PA/t-PA activation and consequently plasminogen, MMPs, and TGF- $\beta$ activation, thus retarding ECM turnover ${ }^{3,15,16,57}$. However, pathologically prolonged low ECM degradation leads to the excessive collagen accumulation. Numerous studies show the protective effects of PAI-1 deficiency toward induced fibrosis of most organs, except for skin and spontaneous age-relat-

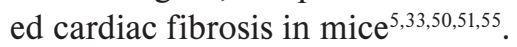

Interestingly, spontaneous age-related cardiac fibrosis in PAI-1 null mice is not associated with significant fibrosis after MI. Macrophage specific u-PA overexpression in these animals significantly contributes to the process ${ }^{58}$. Moreover, PAI-1 maintains endothelial integrity and permeability by controlling the vascular endothelial cadherin trafficking. Disruption of the cadherin junctions leads to increased endothelial permeability ${ }^{59}$. Microvascular leakage in PAI-1 (-/-) mice was shown to contribute to cardiac fibrosis through enhanced local inflammation. Fibrosis with extensive interstitial collagen accumulation develops spontaneously and progressively with aging. Expression of MMP-2, MMP-9, u-PA, and tissue inhibitor of MMP-2 were elevated in PAI-1 (-/-) mice, while increased TGF- $\beta$ levels and signaling led to increased endothelial to mesenchymal transition. Due to all these facts PAI-1 is suggested to have a cardioprotective role concerning fibrosis ${ }^{3,55}$.

Pulmonary fibrosis involves alveolar epithelial injury. In an alveolar epithelial cell wounding model u-PA deficiency negatively affected wound closure, while PAI-1 deficiency significantly enhanced healing efficiency. The negative effect of PAI-1 to alveolar repair was explained by its binding to $\mathrm{VN}$, because enhanced alveolar epithelial cell motility is determined by $\mathrm{VN}$ availability. $\mathrm{VN}$ accumulates at the sites of exudates pulling along PAI-1 at the sites of injury, where it can initially inhibit fibrin degradation and later matrix turnover ${ }^{32,50,60}$. Environmental pollutants (nickel, silica) may exacerbate lung injury as they are capable of inducing PAI-1 expression through the activity of ERK1/2 MAPK pathways. Additionally, alveolar macrophages can generate plasmin, suggesting potential activation of TGF- $\beta$ after injury ${ }^{58,61}$.

PAI-1 deficiency is reported to protect the lungs from excessive fibrin accumulation and fibrosis. This effect may partly be explained through the enhanced fibrinolytic activity. Secondly, TGF- $\beta$ failed to induce epithelial to mesenchymal transition in these animals ${ }^{3}$. One recent study reported an additional mechanism that protects PAI-1 deficient mice from lung fibrosis. That is an elevated production of prostaglandin E2 through the plasmin/hepatocyte growth factor (HGF)/COX-2 axis, an anti-fibrotic mediator associated with increased plasmin generation ${ }^{62}$.

PAI-1 expression and levels had been found increased in many fibrotic renal diseases characterized by ECM accumulation and experimental models of glomerulosclerosis $^{3,63,64}$. Elevated TGF- $\beta$ and RAA system components in renal diseases pathogenesis contribute to the enhanced PAI-1 expression ${ }^{65}$. The results of experimental studies on PAI-1 role in renal fibrosis are often contradictory, mainly due to different models used, especially relating to the aggressiveness and speed at which the kidney injury develops.

In rapidly developing kidney disease, the inflammatory reaction is dominant and PAI-1 effect is directed toward macrophage migration and TGF- $\beta 1$ activation ${ }^{65}$. PAI- 1 activation occurs in the early phase of glomerular injury, which is associated with cell migration. In the antibodies induced glomerulonephritis the inhibition of endogenous PAI-1 reduced inflammatory cell infiltration. The number of monocytes/macrophages per glomerular cross section was reduced, leading consequently to reduction of glomerulosclerosis ${ }^{60}$. The PAI-1 (-/-) mice had significantly lower number of interstitial macrophages and myofibroblasts than WT at day 3 after the unilateral ureteral obstruction injury. Additionally, decreased cellularity was associated with reduced TGF- $\beta$ and procollagens expression ${ }^{66}$.

PAI- 1 and TGF- $\beta$ seem to be in intricate relation influenced by tissue cellularity, especially inflammatory cell infiltration, and by different cytokines and hormones present. TGF- $\beta 1$ stimulates collagen deposition in both glomerular and interstitial ECM, and PAI-1 deficiency hinders this effect. In the study of a slowly progressive TGF- $\beta 1$-induced kidney injury, which lacks a major inflammatory component, TGF- $\beta 1$ overexpression stimulated PAI-1 mRNA and interstitial collagen deposition, while PAI-1 null mice showed reduced collagen expression and accumulation. The beneficial effect of PAI-1 deficiency was not due to immunomodulation or fibrinolysis, but to the impeded ECM synthesis. A proposed mechanism is PAI-1 interference with the integrin to VN binding and/or compensatory increase in other PAs inhibitors ${ }^{65}$.

PAI-1 deficient mice were protected against interstitial fibrosis after 12 weeks aldosterone administration ${ }^{57}$. AII causes dual stimulation of PAI-1 transcription: A rapid one - directed to PAI-1 gene up-regulation in the early phase, and a later one that is indirect and mediated by TGF- $\beta$. AII up-regulates TGF- $\beta$ gene and thus stimulates ECM synthesis, so that prolonged effect of AII on PAI-1 protein synthesis depends on concomitant TGF- $\beta$ activity $^{57,60}$.

Several plasmin independent pathways are discussed for decreased total collagen content in the aldosterone treated PAI-1 null mice with ECM degradation. Increased MMP-2 activity is one of the mechanisms, as it is higher in PAI-1 null mice than WT. Nevertheless, decreased MMPs activity in diabetic PAI null mice argues that ECM degradation is the major cause of attenuated fibrosis ${ }^{57,60,64}$. Another suggestion is the action of osteopontin, a proinflammatory mediator and adhesin, which is induced by aldosterone. It can stimulate vascular SMCs proliferation and migration, and contributes to macrophages recruitment. Its expression was found significantly lower in PAI-1 (-/-) mice. Physiologically, osteopontin is produced when cell's integrins bind to a collagen or fibronectin, thus PAI-1 deficiency-mediated ECM degradation may attenuate this reaction ${ }^{60,67}$. 
The PAI-1 role in liver fibrogenesis was demonstrated in a rat model where antifibrotic drug (interferon (IFN)- $\alpha$ $2 \mathrm{a})$ led to reduced collagen and PAI-1 production and subsequently amelioration of the cirrhosis ${ }^{68}$. Abdominal adhesions formation after hepatectomy is influenced by natural killer (NK) cells and their production of IFN- $\gamma$, which seems to be the key regulator of this process through the balance of PAI-1/t-PA levels. That is, marked increase of PAI-1 and decrease of t-PA expression. The HGF (anti-fibrotic agent) was shown to inhibit adhesion formation as it reduces IFN- $\gamma$ and PAI-1 levels, but increases t-PA $\left(\right.$ ref. $^{69}$ ).

\section{THE ROLE OF PAI-1 IN EMBRYO IMPLANTATION AND PLACENTATION}

The plasminogen system is believed to regulate maternal tissue remodeling during embryonal implantation, through successful trophoblast invasion and uteroplacental vasculature adaptation. Different distribution and time coordination of PAs and their inhibitors (PAI-1 and PAI2) have important fibrinolytic roles in the early stages of placenta formation as well as its separation from maternal tissue during birth ${ }^{7,70}$.

Prostaglandins regulate trophoblast invasion in early pregnancy by stimulation of PAI-1 and inhibition of MMPs expression in stromal cells ${ }^{71}$. Likewise, glucocorticoids have an important effect on trophoblast growth and ECM degradation during invasion through the increase of PAs with fibrinolysis which is necessary for efficient vascularization. Dexamethasone was observed to significantly enhance TGF- $\beta$ dependent PAI-1 expression in cytotrophoblasts in vitro, unlike estradiol, prostaglandins or testosterone. If elevated, PAI-1 could counteract fibrinolysis and potentially impair placental blood exchange leading to pre-eclampsia (PE) and intrauterine growth retardation (IUGR). These pregnancies were accompanied by excessive ThPAI-1 levels in placenta together with abnormal fibrin deposition. Among others, glucocorticoid receptor and RAA signaling pathways are found significantly involved in preterm PE placenta tissues ${ }^{70,72}$.

Uterine NK cells produce several cytokines and growth factors that affect trophoblast invasion. These cytokines (TNF- $\alpha$, TGF- $\beta$, IFN- $\gamma$ ) were shown to inhibit extravillous cytotrophoblast (EVT) invasion in vitro. Mechanisms of action included down-regulation of MMPs and u-PA, upregulation of PAI-1, and increased apoptosis ${ }^{71,73}$. TNF- $\alpha$ increases apoptosis of villous cytotrophoblast cells and stimulates expression of PAI-1, u-PA and MMP-9 by EVT (ref. $\left.{ }^{74}\right)$.

Increased PAI-1 levels are speculated to cause impaired proteolysis and promote fibrin deposition thus limiting trophoblast advancement which may favor unexplained early recurrent miscarriage ${ }^{7}$. Increased fibrin deposition with low trophoblast invasion and thrombolysis results in microthrombosis with further hypoxia and nutrition depletion. Matching changes were found in placental vascular bed biopsies, showing defective deep placentation with restricted remodeling and obstructions in the myometrial segment of the spiral arteries ${ }^{75}$. Homozygosity of PAI-1 4G/5G, or compound carrier status with FXIII Val34Leu mutation, significantly increased the overall relative risk for early recurrent pregnancy loss ${ }^{7}$.

Several clinical studies associated altered PAI-1 functionality to development of pregnancy related complications, specifically PE and IUGR. PAI-1 blood levels were found increased in these patients, along with high placental expression, suggesting the placenta is the primary source for its increased serum concentrations. Villous syncytiotrophoblast was found responsible for this enhanced PAI-1 expression and reduced perivillous fibrinolysis in patients. In contrast, PAI-2 levels were reduced in placenta $^{70,76}$.

Venous umbilical PAI-1 was significantly increased ( 10-fold) in hypoxemic placental insufficiency compared to controls. These levels had a positive predictive ratio of 6.7, suggesting that circulating PAI-1 levels can be used as an indicator of placental insufficiency ${ }^{77}$. PAI-1 umbilical blood levels were positively associated with plasma's angiogenic potency (in vitro) demonstrating the role of PAI-1 in angiogenic regulation in growth restricted pregnancies. The proangiogenic activity of PAI-1 is thought to be related to the composition of stable ECM and therefore cell migration and proliferation ${ }^{78}$.

\section{THE ROLE OF PAI-1 IN CANCER METASTASIS}

As a number of studies demonstrate, u-PA and PAI1 have strong prognostic and predictive value as cancer biomarkers ${ }^{19,28,78,79}$. Their levels in primary tumor breast tissue extracts can distinguish patients risk of disease recurrence. In the long-term follow-up study u-PA and PAI-1 levels strongly indicated an aggressive course of lymph node-negative breast cancer, independent of the HER2 status. Their low levels in primary tumors were associated with a very good prognosis, in contrast to high values that were connected to increased risk of relapse, despite negative nodes. Therefore, the American Society of Clinical Oncology has recommended their assessment for adjuvant chemotherapy use in node-negative breast cancer patients ${ }^{79,80}$.

ECM degradation is one of the crucial events in cancer metastasis. Proteolytic enzymes (MMPs and plasminogen system) secreted by tumor and inflammatory cells enable this process ${ }^{81}$. Cancer cells can use the u-PA system in multiple ways. By overexpressing pro-u-PA, u-PAR and plasminogen receptors, malignant cells can generate plasmin de novo on the membrane surface or in close vicinity, aiming for suitable microenvironment for its progression. By producing specific inhibitors (PAI-1 and PAI-2) they also regulate PAs (ref. ${ }^{11,28,35}$ ).

Myoepithelial cells of ductal carcinoma in situ (DCIS) express components of plasminogen system and their uPAR to VN bond helps in cell-matrix interaction, thus controlling cell adhesion or detachment. It is speculated that PAI-1 could cause an interruption of myoepithelial cell layer and the loss of anti-invasive DCIS properties ${ }^{82}$. However, u-PAR expression was observed in invasive duc- 
tal carcinoma infiltration, but not in DICS. While u-PA and PAI-1 were detected in both types, with stronger expression in invasive carcinoma. PAI-1 anti-proteolytic activity at the initial stage, when u-PAR is not expressed, may prevent cancer spreading, however at later stages when the expression of other u-PA components is established, different mechanisms are employed. Therefore, direct cancer proteolysis of ECM can be counteracted by PAI-1, but increased PAI-1 may also influence cell detachment $^{28}$.

PAI-1 shows chemokine-like activity as it increases filopodia formation and cell migration of invasive cell lines. u-PAR and u-PA were found co-localized with chemokine receptors at the leading edge of fast-migrating cells, whereas PAI-1 was adsorbed on ECM and when in high concentrations it promoted migration ${ }^{28,83}$. Another mechanism of the most aggressive cancer cells involves employment of matrix-bound PAI-1 for mesenchymalamoeboid transition and metastatic escape. The new mechanism involves amoeboid migration and cell blebbing, where PAI-1 maintains these processes by localizing phosphoinositide-dependent kinase-1 and ROCK1 (Rhoassociated Coil-containing Protein Kinase 1) at the cell membrane and mediating activation of RhoA/ROCK1/ MLC-P (Myosin Light Chain) pathway ${ }^{21}$.

This aside, lack of plasminogen was shown to reduce angiogenesis $^{35,53}$. In contrast, PAI-1 promoted tumor angiogenesis, but not through the facilitated ECs migration via ECM interaction. The emphasis is on proteolysis as the salient mechanism of tumor angiogenesis. However, the process requires tumor induction of host microvessels and must be balanced by additional factors that provide vessel stabilization and maturation ${ }^{78}$.

\section{CONCLUSION}

The function of PAI-1 is not restricted to the inhibition of intravascular fibrinolysis but is also important in a vast number of tissue remodeling processes that involve cell motility and their interactions with ECM. PAI-1 is a component of early cellular response to injury and by reacting with membrane surface proteins it participates in cell adhesion and initiation of intracellular signaling, specifically cytoskeletal reorganization. The complexity of ECM remodeling resides in varying relation of the plasminogen system components and other matrix constituents. The mechanisms of PAI-1 action are affected by inflammatory mediators and cytokines, among which TGF- $\beta$ and INF- $\gamma$ are in interdependent relation with PAI-1. Targeting and/ or alteration of PAI-1 functions might provide benefit to future therapeutic approaches in diseases where ECM undergoes substantial remodeling.

\section{Search strategy and selection criteria}

Our research strategy was aimed at evaluating studies on the role of plasminogen activator inhibitor 1 regarding molecular mechanisms in stromal remodeling, in order to comprehend and summarize the current knowledge of PAI-1 involvement in this processes. Scientific articles from 1980 to 2017 were searched using the PubMed and Web of Science databases.

\section{ABBREVIATIONS}

AII, Angiotensin II; CRP, C- reactive protein; DCIS, Ductal carcinoma in situ; EC, Endothelial cells; ECM, Extracellular matrix; ERK, Extracellular-regulated signal kinase; EVT, Extravillous cytotrophoblast; FGF, $\beta$-fibroblast growth factor; HGF, Hepatocyte growth factor; IFN, Interferon; IL-1, Interleukin-1; IUGR, Intrauterine growth retardation; KO, Knockout; LDL, Low-density lipoprotein; LRP, Low-density lipoprotein (LDL) receptor-related protein (LRP); LV, Left ventricle; MAPK, Mitogen-activated protein kinase; MI, Myocardial infarction; MLC-P, Myosin light chain; MMP, Matrix metalloproteinases; MPO, Myeloperoxidase; NF-кB, Nuclear factor kappa B; NK, Natural killer; PA, Plasminogen activator; PAI-1, Plasminogen activator inhibitor type 1; PE, Pre-eclampsia; RAA, Renin-angiotensin-aldosterone; ROCK1, Rho-associated Coil-containing Protein Kinase 1; SMC, Smooth muscle cells; TGF $\beta$, Transforming growth factor- $\beta$; TNF- $\alpha$, Tumor necrosis factor- $\alpha$; t-PA, Tissue plasminogen activator; u-PA, Urokinase plasminogen activator; VN, Vitronectin; WT, Wild-type.

Acknowledgments: The work is supported by the Project No. 41018 of the Ministry of Education, Science and Technical Development of the Republic of Serbia, and the Internal Project No. 3 of the Faculty of Medicine, University of Nis, Serbia.

Author contributions: All authors participated in gathering information for the work, review of the literature, writing and analyzing the text of the manuscript.

Conflict of interest statement: The authors state that there are no conflicts of interest regarding the publication of this article. None declared.

\section{REFERENCES}

1. Yasar Yildiz S, Kuru P, Toksoy Oner E, Agirbasli M. Functional Stability of Plasminogen Activator Inhibitor-1. ScientificWorldJournal 2014;2014:858293.

2. Vaughan DE. PAI-1 and atherothrombosis. J Thromb Hemost 2005;3(8):1879-83.

3. Ghosh AK, Vaughan DE. PAI-1 in Tissue Fibrosis. J Cell Physiol 2012;227(2):493-507.

4. Lijnen HR. Pleiotropic functions of plasminogen activator inhibitor-1. J Thromb Hemost 2005;3(1):35-45.

5. D'Elia JA, Bayliss G, Gleason RE, Weinrauch LA. Cardiovascular-renal complications and the possible role of plasminogen activator inhibitor: a review. Clin Kidney J 2016;9(5):705-12.

6. Koch W, Schrempf M, Erl A, Mueller JC, Hoppmann P, Schömig A, Kastrati A. 4G/5G polymorphism and haplotypes of SERPINE1 in atherosclerotic diseases of coronary arteries. Thromb Haemost 2010;103(6):1170-80.

7. Dossenbach-Glaninger $A$, van Trotsenburg $M$, Dossenbach M, Oberkanins C, Moritz A, Krugluger W, Huber J, Hopmeier P. Plasminogen Activator Inhibitor $14 \mathrm{G} / 5 \mathrm{G}$ Polymorphism and Coagulation Factor XIII Val34Leu Polymorphism: Impaired Fibrinolysis and Early Pregnancy Loss. Clin Chem 2003;49(7):1081-6.

8. Kasza A, Kiss DL, Gopalan S, Xu W, Rydel RE, Koj A, Kordula T. Mechanism of Plasminogen Activator Inhibitor-1 regulation by 
Oncostatin $\mathrm{M}$ and Interleukin-1 in human astrocytes. J Neurochem 2002; 83(3):696-703.

9. Chen YQ, Sloan-Lancaster J, Berg DT, Richardson MA, Grinnell B, Tseng-Crank J. Differential mechanisms of plasminogen activator inhibitor-1 gene activation by transforming growth factor-beta and tumor necrosis factor-alpha in endothelial cells. Thromb Haemost 2001;86(6):1563-72.

10. Sieuwerts AM, Martens JW, Dorssers LC, Klijn JG, Foekens JA. Differential effects of fibroblast growth factors on expression of genes of the plasminogen activator and insulin-like growth factor systems by human breast fibroblasts. Thromb Haemost 2002;87(4):674-83.

11. McEachron TA, Church FC, Mackman N. Regulation of thrombininduced plasminogen activator inhibitor-1 in 4T1 murine breast cancer cells. Blood Coagul Fibrinolysis 2011;22(7):576-82.

12. Jensen JK, Gettins PG. High-resolution structure of the stable plasminogen activator inhibitor type-1 variant $14-1 B$ in its protein ase-cleaved form: a new tool for detailed interaction studies and modeling. Protein Science 2008;17(10):1844-9.

13. Liu RM. Oxidative Stress, Plasminogen Activator Inhibitor 1, and Lung Fibrosis. Antioxid Redox Signal 2008;10(2):303-19.

14. Boncela J, Papiewska I, Fijalkowska I, Walkowiak B, Cierniewski CS. Acute Phase Protein a1-Acid Glycoprotein Interacts with Plasminogen Activator Inhibitor Type 1 and Stabilizes Its Inhibitory Activity. J Biol Chem 2001;276(38):35305-11.

15. Maquerlot F, Galiacy S, Malo M, Guignabert C, Lawrence DA, d'Ortho MP, Barlovatz-Meimon G. Dual role for plasminogen activator inhibitor type 1 as soluble and as matricellular regulator of epithelia alveolar cell wound healing. Am J Pathol 2006;169(5):1624-32.

16. De Lorenzi V, Sarra Ferraris GM, Madsen JB, Lupia M, Andreasen PA, Sidenius N. Urokinase links plasminogen activation and cell adhesion by cleavage of the RGD motif in vitronectin. EMBO Rep 2016;17(7):982-98.

17. Planus E, Barlovatz-Meimon G, Rogers RA, Bonavaud S, Ingber DE, Wang N. Binding of urokinase to plasminogen activator inhibitor type-1 mediates cell adhesion and spreading. J Cell Sci 1997;110(Pt 9):1091-8.

18. Qi L, Higgins SP, Lu Q, Samarakoon R, Wilkins-Port CE, Ye Q, Higgins CE, Staiano-Coico L, Higgins PJ. SERPINE1 (PAI-1) is a prominent member of the early G0 --> G1 transition "wound repair" transcriptome in p53 mutant human keratinocytes. J Invest Dermato 2008;128(3):749-53.

19. Czekay RP, Loskutoff DJ. Unexpected role of plasminogen activator inhibitor 1 in cell adhesion and detachment. Exp Biol Med (Maywood) 2004;229(11):1090-6.

20. Czekay RP, Aertgeerts K, Curriden SA, Loskutoff DJ. Plasminogen activator inhibitor-1 detaches cells from extracellular matrices by inactivating integrins. J Cell Biol 2003;160:781-91.

21. Cartier-Michaud A, Malo M, Charrière-Bertrand C, Gadea G, Anguille C, Supiramaniam A, Lesne A, Delaplace F, Hutzler G, Roux P, Lawrence DA, Barlovatz-Meimon G. Matrix-Bound PAl-1 Supports Cell Blebbing via RhoA/ROCK1 Signaling. PLoS One 2012;7(2):e32204.

22. Minor KH, Peterson CB. Plasminogen activator inhibitor type 1 promotes the self-association of vitronectin into complexes exhibiting altered incorporation into the extracellular matrix. J Biol Chem 2002;277:10337-45.

23. Nguyen DH, Catling AD, Webb DJ, Sankovic M, Walker LA, Somlyo $A V$, Weber MJ, Gonias SL. Myosin light chain kinase functions downstream of Ras/ERK to promote migration of urokinase-type plasminogen activator-stimulated cells in an integrin-selective manner J Cell Biol 1999;146:149-64.

24. Stefansson S, Lawrence DA. The serpin PAl-1 inhibits cell migration by blocking integrin av $\beta 3$ binding to vitronectin. Nature 1996;383:441-3.

25. Schroeck F, Arroyo de Prada N, Sperl S, Schmitt M, Viktor M. Interaction of plasminogen activator inhibitor type-1 (PAl-1) with vitronectin ( Vn): mapping the binding sites on PAl-1 and Vn. Bio Chem 2002;383(7-8):1143-9.

26. Garg N, Goyal N, Strawn TL, Wu J, Mann KM, Lawrence DA, Fay WP. Plasminogen activator inhibitor- 1 and vitronectin expression level and stoichiometry regulate vascular smooth muscle cell migration through physiological collagen matrices. Thromb Haemost 2010;8(8):1847-54.

27. Czekay RP, Kuemmel TA, Orlando RA, Farquhar MG. Direct binding of occupied urokinase receptor (UPAR) to LDL receptor-related protein is required for endocytosis of UPAR and regulation of cell surface urokinase activity. Mol Biol Cell 2001;12:1467-79.

28. Chazaud B, Ricoux R, Christov C, Plonquet A, Gherardi RK, BarlovatzMeimon G. Promigratory effect of plasminogen activator inhibitor-1 on invasive breast cancer cell populations. Am J Pathol 2002;160(1):237-46.

30. Stefansson S, Lawrence DA. Old dogs and new tricks: proteases, inhibitors, and cell migration. Sci STKE 2003;(189):pe24.

31. Degryse B, Neels JG, Czekay R-P, Aertgeerts K, Kamikubo Y, Loskutoff $D J$. The low density lipoprotein receptor-related protein is a motogenic receptor for plasminogen activator inhlbitor-I. J Biol Chern 2004;279:22595-604.

32. Lazar MH, Christensen PJ, Du M, Yu B, Subbotina NM, Hanson KE, Hansen JM, White ES, Simon RH, Sisson TH. Plasminogen activator inhibitor-1 impairs alveolar epithelial repair by binding to vitronectin. Am J Respir Cell Mol Biol 2004;31(6):672-8.

33. Chan JC, Duszczyszyn DA, Castellino FJ, Ploplis VA. Accelerated skin wound healing in plasminogen activator inhibitor-1-deficient mice. Am J Pathol 2001;159:1681-8.

34. Hasenstab D, Lea H, Clowes AW. Local Plasminogen Activator Inhibitor Type 1 Overexpression in Rat Carotid Artery Enhances Thrombosis and Endothelial Regeneration While Inhibiting Intimal Thickening. Arterioscler Thromb Vasc Biol 2000;20:853-9.

35. Lacroix R, Sabatier F, Mialhe A, Basire A, Pannell R, Borghi H, Robert S, Lamy E, Plawinski L, Camoin-Jau L, Gurewich V, Angles-Cano E, Dignat-George F. Activation of plasminogen into plasmin at the surface of endothelial microparticles: a mechanism that modulates angiogenic properties of endothelial progenitor cells in vitro. Blood 2007;110(7):2432-9.

36. de Waard V, Arkenbout EK, Carmeliet P, Lindner V, Pannekoek H Plasminogen activator inhibitor 1 and vitronectin protect against stenosis in a murine carotid artery ligation model. Arterioscler Thromb Vasc Biol 2002;22(12):1978-83.

37. Konstantinides S, Schäfer K, Loskutoff DJ. Do PAl-1 and Vitronectin Promote or Inhibit Neointima Formation? The Exact Role of the Fibrinolytic System in Vascular Remodeling Remains Uncertain. Arterioscler Thromb Vasc Biol 2002;22:1943-5.

38. Peng L, Bhatia N, Parker AC, Zhu Y, Fay WP. Endogenous Vitronectin and Plasminogen Activator Inhibitor-1 Promote Neointima Formation in Murine Carotid Arteries. Arterioscler Thromb Vasc Biol 2002;22:934-9.

39. Stoop AA, Lupu F, Pannekoek H. Colocalization of Thrombin, PAI1 , and Vitronectin in the Atherosclerotic Vessel Wall A Potential Regulatory Mechanism of Thrombin Activity by PAI-1/Vitronectin Complexes. Arterioscler Thromb Vasc Biol 2000;20:1143-9.

40. Podor TJ, Peterson CB, Lawrence DA, Stefansson S, Shaughnessy SG, Foulon DM, Butcher M, Weitz JI. Type 1 plasminogen activator inhibitor binds to fibrin via vitronectin. J Biol Chem 2000; 275:19788-94.

41. Lijnen HR, Van Hoef B, Umans K, Collen D. Neointima formation and thrombosis after vascular injury in transgenic mice overexpressing plasminogen activator inhibitor-1 (PAl-1). J Thromb Haemost 2004;2:16-22.

42. Hasenstab D, Forough R, Clowes AW. Plasminogen activator inhibitor type 1 and tissue inhibitor of metalloproteinases- 2 increase after arterial injury in rats. Circ Res 1997 Apr;80(4):490-6.

43. Keeton MR, Curriden SA, van Zonneveld AJ, Loskutoff DJ. Identification of regulatory sequences in the type 1 plasminogen activator inhibitor gene responsive to transforming growth factor beta. J Biol Chem 1991;266:23048-52.

44. Otsuka G, Agah R, Frutkin AD, Wight TN, Dichek DA. Transforming growth factor beta 1 induces neointima formation through plasminogen activator inhibitor-1-dependent pathways. Arterioscler Thromb Vasc Biol 2006;26(4):737-43.

45. Boncela J, Przygodzka P, Papiewska-Pajak I, Wyroba E, Osinska M, Cierniewski CS. Plasminogen activator inhibitor type 1 interacts with alpha3 subunit of proteasome and modulates its activity. J Biol Chem 2011; 286:6820-31.

46. Soeki T, Tamura Y, Shinohara H, Sakabe K, Onose Y, Fukuda N. Plasma concentrations of fibrinolytic factors in the subacute phase of myocardial infarction predict recurrent myocardial infarction or sudden cardiac death. Int J Cardiol 2002;85:277-83.

47. Lupu F, Heim DA, Bachmann F, Hurni M, Kakkar VV, Kruithof EK. Plasminogen activator expression in human atherosclerotic lesions. Arterioscler Thromb Vasc Biol 1995;15:1444-55.

48. JiY, Fish PM, Strawn TL, Lohman AW, Wu J, Szalai AJ, Fay WP. C-Reactive 
Protein Induces Expression of Tissue Factor and Plasminogen Activator Inhibitor-1 and Promotes Fibrin Accumulation in Vein Grafts. J Thromb Haemost 2014;12(10):1667-77.

49. Chen C, Nan B, Lin P, Yao Q. C-reactive protein increases plasminogen activator inhibitor-1 expression in human endothelial cells. Thromb Res 2008;122:125-33.

50. Pate GE, Walinski HP, Bohunek L, Podor TJ. Validation of the vitronectin knockout mouse as a model for studying myocardial infarction: Vitronectin appears to influence left ventricular remodelling following myocardial infarction. Exp Clin Cardiol 2013;18(1):43-7.

51. Takeshita K, Hayashi M, lino S, Kondo $T$, Inden $Y$, Iwase M, Kojima T, Hirai M, Ito M, Loskutoff DJ, Saito H, Murohara T, Yamamoto K. Increased expression of plasminogen activator inhibitor-1 in cardio myocytes contributes to cardiac fibrosis after myocardial infarction. Am J Pathol 2004;164:449-56.

52. Askari AT, Brennan ML, Zhou X, Drinko J, Morehead A, Thomas JD, Topol EJ, Hazen SL, Penn MS. Myeloperoxidase and plasminogen activator inhibitor 1 play a central role in ventricular remodeling after myocardial infarction. J Exp Med 2003;197(5):615-24.

53. Heymans S, Luttun A, Nuyens D, Theilmeier G, Creemers E, Moons L, Dyspersin GD, Cleutjens JP, Shipley M, Angellilo A, Levi M, Nübe O, Baker A, Keshet E, Lupu F, Herbert JM, Smits JF, Shapiro SD, Baes M, Borgers M, Collen D, Daemen MJ, Carmeliet P. Inhibition of plasminogen activators or matrix metalloproteinases prevents cardiac rupture but impairs therapeutic angiogenesis and causes cardiac failure. Nat Med 1999;5(10):1135-42.

54. Creemers E, Cleutjens J, Smits J, Heymans S, Moons L, Collen D, Daemen M, Carmeliet P. Disruption of the plasminogen gene in mice abolishes wound healing after myocardial infarction. Am J Patho 2000;156:1865-73.

55. Xu Z, Castellino FJ, Ploplis VA. Plasminogen activator inhibitor-1 (PAI1 ) is cardioprotective in mice by maintaining microvascular integrity and cardiac architecture. Blood 2010; 115(10):2038-47.

56. Krenning G, Zeisberg EM, Kalluri R. The origin of fibroblasts and mechanism of cardiac fibrosis. J Cell Physiol 2010;225:631-7.

57. Ma LJ, Fogo AB. PAI-1 and kidney fibrosis. Front Biosci 2009;14:202841.

58. Moriwaki $H$, Stempien-Otero A, Kremen M, Cozen AE, Dichek DA Overexpression of urokinase by macrophages or deficiency of plasminogen activator inhibitor type 1 causes cardiac fibrosis in mice. Circ Res 2004;95:637-44.

59. Daniel AE, Timmerman I, Kovacevic I, Hordijk PL, Adriaanse L, Paatero I, Belting HG, van Buul JD. Plasminogen Activator Inhibitor-1 Controls Vascular Integrity by Regulating VE-Cadherin Trafficking. PLoS One 2015;10(12):e0145684.

60. Huang Y, Haraguchi M, Lawrence DA, Border WA, Yu L, Noble NA. A mutant, noninhibitory plasminogen activator inhibitor type 1 decreases matrix accumulation in experimental glomerulonephritis. J Clin Invest 2003;112(3):379-88.

61. Khalil N, Corne S, Whitman C, Yacyshyn H. Plasmin regulates the activation of cell-associated latent TGF-beta 1 secreted by rat alveolar macrophages after in vivo bleomycin injury. Am J Respir Cell Mol Biol 1996;15(2):252-9.

62. Bauman KA, Wettlaufer SH, Okunishi K, Vannella KM, Stoolman JS, Huang SK, Courey AJ, White ES, Hogaboam CM, Simon RH, Toews GB, Sisson TH, Moore BB, Peters-Golden M. The antifibrotic effects of plasminogen activation occur via prostaglandin E2 synthesis in humans and mice. Clin Invest 2010;120:1950-60.

63. Barnes JL, Mitchell RJ, Torres ES. Expression of plasminogen activator inhibitor-1 (PAl-1) during cellular remodeling in proliferative glomerulonephritis in the rat. J Histochem Cytochem 1995;43(9):895-905.

64. Kaikita K, Fogo AB, Ma LJ, Schoenhard JA, Brown NJ, Vaughan DE. Plasminogen activator inhibitor-1 deficiency prevents hypertension and vascular fibrosis in response to long-term nitric oxide synthase inhibition. Circulation 2001;104:839-44.

65. Krag S, Danielsen CC, Carmeliet P, Nyengaard J, Wogensen L. Plasminogen activator inhibitor-1 gene deficiency attenuates TGFbeta1-induced kidney disease. Kidney Int 2005; 68:2651-66.

66. Oda T, Jung YO, Kim HS, Cai X, López-Guisa JM, Ikeda Y, Eddy AA PAl-1 deficiency attenuates the fibrogenic response to ureteral obstruction. Kidney Int 2001;60:587-96.
67. Shik J, Parfrey PS. The clinical epidemiology of cardiovascular disease in chronic kidney disease. Curr Opin Nephrol Hypertens 2005; 14:550-7.

68. García L, Hernández I, Sandoval A, Salazar A, Garcia J, Vera J, Grijalva G, Muriel P, Margolin S, Armendariz-Borunda J. Pirfenidone effectively reverses experimental liver fibrosis. J Hepatol 2002;37:797-805.

69. Ohashi K, Yoshimoto T, Kosaka H, Hirano T, limuro Y, Nakanishi K, Fujimoto J. Interferon $\gamma$ and plasminogen activator inhibitor 1 regulate adhesion formation after partial hepatectomy. Br J Surg 2014;101(4):398-407.

70. Shu C, Liu Z, Cui L, Wei C, Wang S, Tang JJ, Cui M, Lian G, Li W, Liu X, Xu H, Jiang J, Lee P, Zhang DY, He J, Ye F. Protein Profiling of Preeclampsia Placental Tissues. PLoS One 2014;9(11):e112890.

71. Zhu JY, Pang ZJ, Yu YH. Regulation of Trophoblast Invasion: The Role of Matrix Metalloproteinases. Rev Obstet Gynecol 2012;5(3-4):e13743

72. Ma Y, Ryu JS, Dulay A, Segal M, Guller S. Regulation of plasminogen activator inhibitor (PAI)-1 expression in a human trophoblast cell line by glucocorticoid (GC) and transforming growth factor (TGF)-beta. Placenta 2002;23(10):727-34.

73. Lash GE, Otun HA, Innes BA, Percival K, Searle RF, Robson SC, Bulme JN. Regulation of extravillous trophoblast invasion by uterine natural killer cells is dependent on gestational age. Hum Reprod 2010;25(5):1137-45

74. Otun HA, Lash GE, Innes BA, Bulmer JN, Naruse K, Hannon T, Searle $\mathrm{RF}$, Robson SC.Effect of tumour necrosis factor-alpha in combination with interferongamma on first trimester extravillous trophoblast invasion. J Reprod Immunol 2011;88:1-11.

75. Brosens I, Pijnenborg R, Vercruysse L, Romero R. The "Great Obstetrical Syndromes" are associated with disorders of deep placentation. Am J Obstet Gynecol 2011;204(3):193-201

76. Estellés A, Gilabert J, Keeton M, Eguchi Y, Aznar J, Grancha S, Espña F, Loskutoff DJ, Schleef RR. Altered expression of plasminogen activator inhibitor type 1 in placentas from pregnant women with preeclampsia and/or intrauterine fetal growth retardation. Blood 1994;84(1):143-50.

77. Seferovic MD, Gupta MB. Increased Umbilical Cord PAI-1 Levels in Placental Insufficiency Are Associated with Fetal Hypoxia and Angiogenesis. Dis Markers 2016;2016:7124186.

78. Bajou K, Masson V, Gerard RD, Schmitt PM, Albert V, Praus M, Lund LR, Frandsen TL, Brunner N, Dano K, Fusenig NE, Weidle U, Carmeliet G, Loskutoff D, Collen D, Carmeliet P, Foidart JM, Noël A. The plasminogen activator inhibitor PAI-1 controls in vivo tumor vascularization by interaction with proteases, not vitronectin. Implications for antiangiogenic strategies. J Cell Biol 2001;152(4):777-84.

79. Thomssen C, Harbeck N, Dittmer J, Abraha-Spaeth SR, Papendick N, Paradiso A, Lisboa B, Jaenicke F, Schmitt M, Vetter M. Feasibility of Measuring the Prognostic Factors $\mathrm{U}-\mathrm{PA}$ and PAI-1 in Core Needle Biopsy Breast Cancer Specimens. JNCI J Natl Cancer Inst 2009;101(14):1028-9.

80. Zemzoum I, Kates RE, Ross JS, Dettmar P, Dutta M, Henrichs C, Yurdseven S, Höfler H, Kiechle M, Schmitt M, Harbeck N. Invasion factors UPA/PAI-1 and HER2 status provide independent and complementary information on patient outcome in node-negative breast cancer. J Clin Oncol 2003;21(6):1022-8.

81. Barajas-Castañeda LM, Cortés-Gutiérrez E, García-Rodríguez FM, Campos-Rodríguez R, Lara-Padilla E, Enríquez-Rincón F, CastroMussot ME, Figueroa-Arredondo P. Overexpression of MMP-3 and $\mathrm{u}$-PA with Diminished PAI-1 Related to Metastasis in Ductal Breast Cancer Patients Attending a Public Hospital in Mexico City. J Immunol Res 2016;2016:8519648.

82. Hildenbrand $R$, Schaaf $A$. The urokinase-system in tumor tissue stroma of the breast and breast cancer cell invasion. Int J Oncol 2009;34:15-23.

83. Barreiro $\mathrm{O}$, de la Fuente $\mathrm{H}$, Mittelbrunn M, Sánchez-Madrid F. Functional insights on the polarized redistribution of leukocyte integrins and their ligands during leukocyte migration and immune interactions. Immunol Rev 2007;218:147-64. 